\title{
A pilot study examining garment severance damage caused by a trained sharp-weapon user
}

\section{Abstract}

The pilot study summarized in this paper aimed to raise awareness of a gap that exists in the forensic textile science literature about damage caused to clothing by trained sharpweapon users. A male trained in the Filipino martial arts discipline of Eskrima performed attack techniques on a physical model of a male torso covered with a $97 \%$ cotton / $3 \%$ elastane knitted T-shirt i.e. a garment commonly worn by males. Fabric severance appearance created by three different, but commonly available, knives was evaluated. High-speed video was used to capture each attack. After each attack the resulting damage to the garment was assessed. This pilot study highlighted differences in severances associated with weapon selection i.e. not all knives resulted in similar patterns of textile damage. Additionally a mixture of stab and slash severances were observed. The findings demonstrated the possible misinterpretation of textile damage under these circumstances compared to damage patterns reported in the existing forensic textile science literature for more commonly occurring knife attacks (i.e. stabbings).

\section{Keywords}

Textile damage, simulant, T-shirt, martial arts, knife

\section{Introduction}


Knives are the predominant weapon used in homicides in England and Wales (1). During a domestic or unplanned incident, a weapon of convenience is typically used by a person inexperienced in the use of knives (e.g. a kitchen knife). However in some cases, and particularly in premeditated attacks, the purchase of a specific knife may occur, and that weapon may be used by someone with a level of professional expertise (2-4).

Diverse groups of people use sharp-weapons (i.e. knives, spears, swords) professionally. Examples include military personnel, martial arts practitioners and historical re-enactment groups e.g. The Vikings, The Sealed Knot $(5,6)$. The training received by these individuals affects how the sharp-weapon is used, how long an attack might take and the area of the body targeted (7-9). The numerous books that describe elements of sharp-weapon usage can be broadly divided into historical discussions, military tactics, indigenous techniques and martial arts e.g. (7-11). Within most reputable martial arts schools sharp-weapon training is generally reserved for people who have reached a certain level of competence (e.g. first level black belt). This ensures that an individual's character and temperament can be assessed and unsuitable candidates excluded from training. This is not the case with sharpweapon training and anatomical targeting information freely available via the internet.

People who are victims in sharp-weapon attacks are usually clothed. Damage occurs to clothing layers typically in the torso region of the body and are forensically important with respect to weapon identification $(3,12-18)$. An awareness of fibre composition and fabric and garment structure, and how these variables affect textile damage have become increasingly important in forensic textile science e.g. (19-21) Injuries sustained during a sharpweapon attack may be either classified as stab or incised (slash) wounds, and both may occur during a single attack (16). The forensic textile science literature includes studies evaluating fabric severance created from sharp-weapons (21-25) although no studies appear to 
exist that examine severances caused by an expert in sharp-weapon use. The majority of previous studies have concentrated on damage inflicted by a single penetrating stab impact even though homicides usually involve more than one wound (17). Fewer details with respect to damage caused by slash cuts have been reported. These are usually described as occurring by two different actions; (i) chop and drag and (ii) sweeping slash $(25,26)$.

The aim of the pilot study described in this paper was to highlight techniques used by a trained expert sharp-weapon user ( $n=3$ knives) and to evaluate severance appearance. It is acknowledged that this pilot study has limitations with respect to number of participants and knives used but the resulting textile damage and how it differs compared to previously reported knife impact textile damage is important with respect to forensic textile science.

\section{Methods}

A hollow polymeric, headless, retail display male mannequin ${ }^{1}$ was used to create a mold (Figure 1). Select body landmarks were measured on the mannequin according to ISO 7250 12008 (27) (chest circumference $=910 \mathrm{~mm}$ and waist circumference $=740 \mathrm{~mm}$ ).

Figure 1 Retail mannequin used to form the PermaGel ${ }^{\mathrm{TM}}$ mold (a) complete mannequin and (b) front and back sections of mannequin.

\footnotetext{
${ }^{1}$ The Shopfitting Shop Ltd., Unit 4a \& 4b Holmes Chapel Business Park, Manor Lane, Holmes Chapel, Cheshire, CW4 8AF, UK. (http://www.theshopfittingshop.co.uk/)
} 


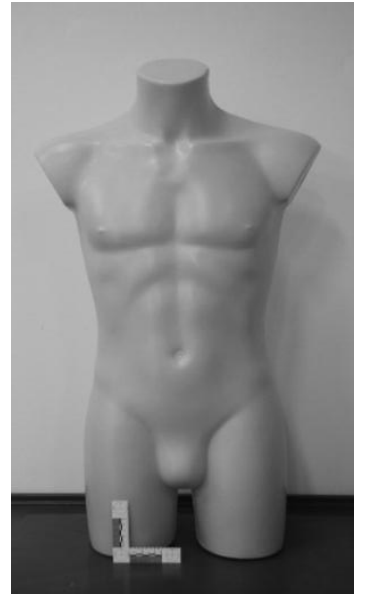

(a)

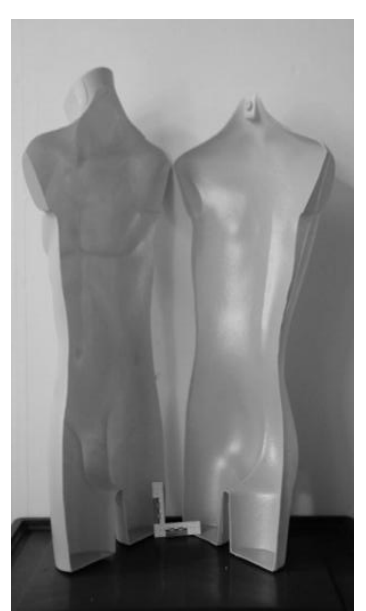

(b)

PermaGel ${ }^{\mathrm{TM}}$, which is used as a simulant for human tissue (28), was used to fill the mold to create three male torsos for testing. Each PermaGel ${ }^{\mathrm{TM}}$ torso was secured to a steel frame (total torso height $=870 \mathrm{~mm}$, height from torso extremity to floor $=708 \mathrm{~mm}$ ) (Figure 2a).

Figure 2 Experimental set-up (a) uncovered PermaGel ${ }^{\mathrm{TM}}$ torso and (b) T-shirt mounted on the PermaGel ${ }^{\mathrm{TM}}$ torso. 


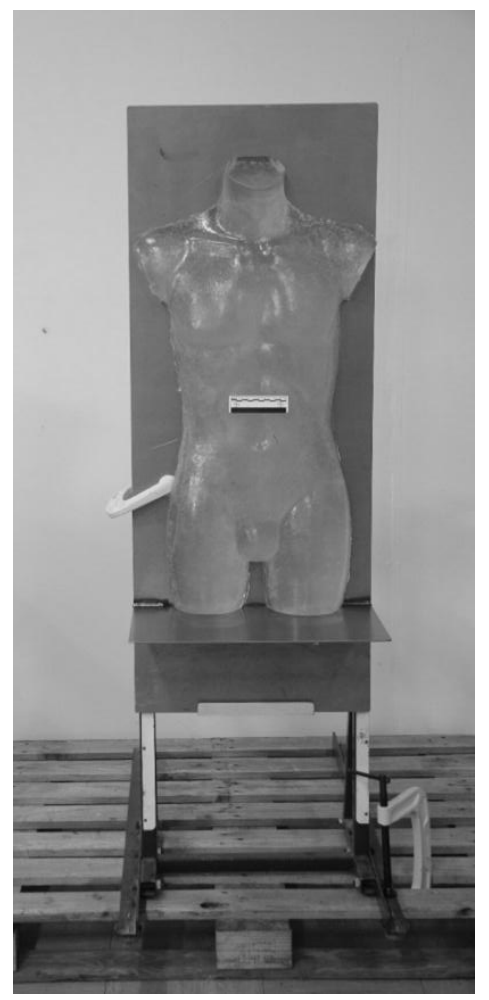

(a)

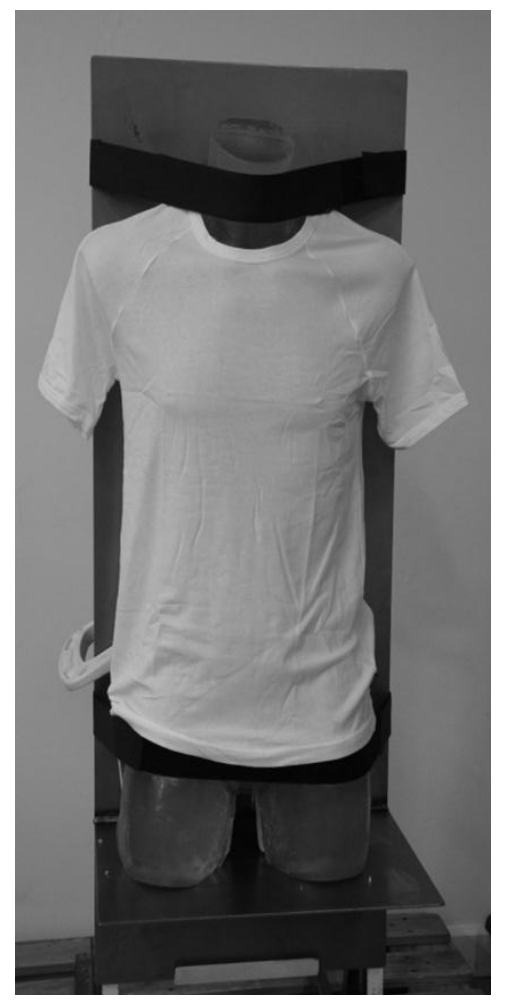

(b)

A mass produced T-shirt was selected for this pilot study as a typical example of clothing covering the male torso ${ }^{2}$. The T-shirts were size small, $97 \%$ cotton / $3 \%$ elastane, bleached white, knitted single jersey, crew neck, short raglan sleeved. T-shirts were laundered before use according to the care instruction label. The T-shirts were then conditioned to $20^{\circ} \mathrm{C} \pm 2{ }^{\circ} \mathrm{C}$ and $65 \%$ R.H. $\pm 4 \%$ R.H in accordance with ISO 139:2005 (29) and selected fabric properties were measured (Table 1).

Table 1 Selected fabric physical properties

\begin{tabular}{|l|l|l|l|l|}
\hline & $\begin{array}{l}\text { Mass per unit } \\
\left(n=5 ; \mathrm{g} / \mathrm{m}^{2}\right)^{\mathrm{a}}\end{array}$ & $\begin{array}{l}\text { Thickness } \\
(n=10 ; \mathrm{mm})^{\mathrm{b}}\end{array}$ & $\begin{array}{l}\text { Wales } \\
(n=5 ; \text { per } \mathrm{cm})^{\mathrm{c}}\end{array}$ & $\begin{array}{l}\text { Courses } \\
(n=5 ; \text { per } \mathrm{cm})^{\mathrm{c}}\end{array}$ \\
\hline
\end{tabular}

\footnotetext{
${ }^{2}$ Bonds Flexits ${ }^{\mathrm{TM}}$ Raglan Tee, Designed in Australia, Made in China. Purchased from Bonds Industries Pty. Ltd, Pacific Brands Clothing Pty. Ltd, 115 Cotham Road, VIC 3101, Australia.
} 


\begin{tabular}{|l|l|l|l|l|}
\hline Mean & 145.5 & 0.548 & 13.0 & 19.0 \\
\hline S.D. & 1.4 & 0.014 & 0.0 & 0.0 \\
\hline
\end{tabular}

AS 2001.2.13: 1987

${ }^{b}$ AS 2001.2.15: 1989 (Procedure A: Static thickness)

${ }^{c}$ AS 2001.2.6: 2001 (Test B: Determination by traversing thread counter)

T-shirts were placed over the PermaGel ${ }^{\mathrm{TM}}$ torso with the center front of the garment in line with the center front of the torso; the bottom opening hung freely as if worn loosely (i.e. not tucked in). The impacted surface was the front of the T-shirt (Figure 2b).

Three different knives were selected for this study:

(i) Mantis Karambit MK-1 Cinq1 (blade length $=51 \mathrm{~mm}$, maximum blade width $=25 \mathrm{~mm}$ ),

(ii) Cold Steel ${ }^{\circledR}$ Culloden $^{\mathrm{TM}}$ (blade length $=127 \mathrm{~mm}$, maximum blade width $=29 \mathrm{~mm}$, and

(iii) Blackhawk XSF ${ }^{\mathrm{TM}}$ Micro Plain (blade length $=81 \mathrm{~mm}$, maximum blade width $=28 \mathrm{~mm}$ ) (Figure 3a-c).

The back (spine, outside edge) of the Mantis Karambit knife was not sharpened i.e. this knife had a single edged flat parallel blade. The belly (inside edge) of the blade had a non-serrated sharpened edge, part of which was concave (approximately three-quarters), the remaining being linear. The Mantis blade was manufactured from $420 \mathrm{HC}$ stainless steel.

The Cold Stee ${ }^{\circledR}$ knife had a double edged blade with one side serrated the whole length and the other serrated for approximately one third the length closet to the handle. The Cold Steel ${ }^{\circledR}$ blade was manufactured from AUS-10A stainless steel. 
The Blackhawk XSF ${ }^{\mathrm{TM}}$ blade is a full-tang and manufactured from AUS-8A stainless steel which is Teflon $^{\circledR}$ coated. The Blackhawk $\mathrm{XSF}^{\mathrm{TM}}$ knife also had a double edged blade which was flat and parallel; neither edge was serrated.

These knives were selected to demonstrate the differences associated with (i) technique during an attack and (ii) effect on fabric severance appearance.

A Niroflex chainmail protective glove was used to protect the trained sharp-weapon user's hand (Figure 3d). 
Figure 3 Experimental knives and personal protective equipment (PPE) (a) Mantis

Karambit MK-1 Cinq1 (b) Cold Steel ${ }^{\circledR}$ Culloden $^{\mathrm{TM}}$ (c) BlackHawk ${ }^{\mathrm{TM}}$ XSF $^{\mathrm{TM}}$ Micro Plain and (d) Niroflex chainmail protective glove.

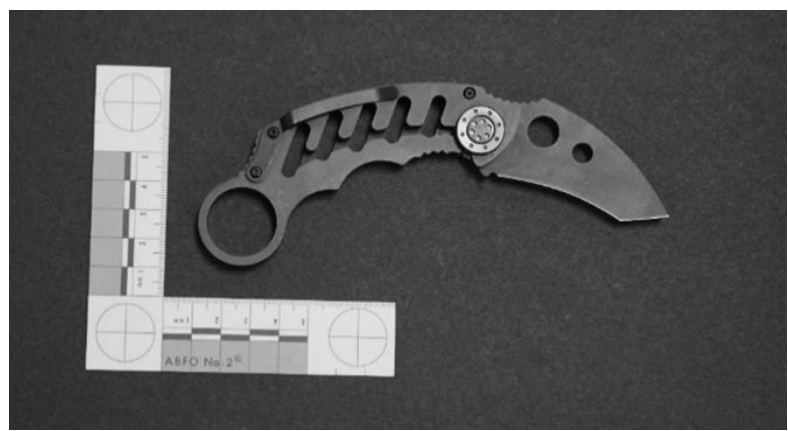

(a)

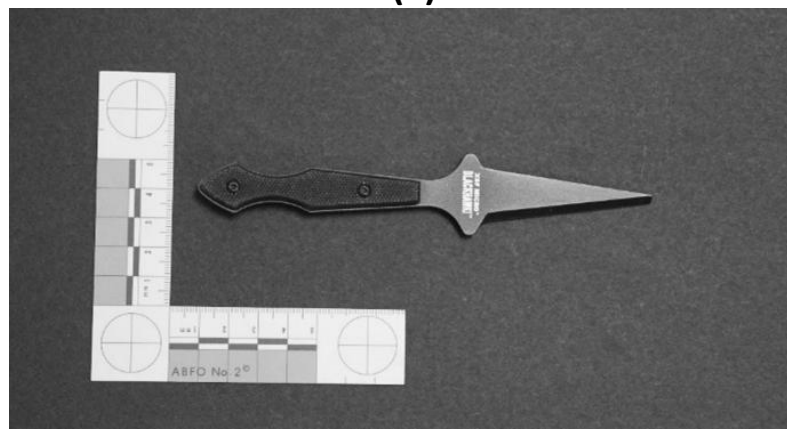

(c)

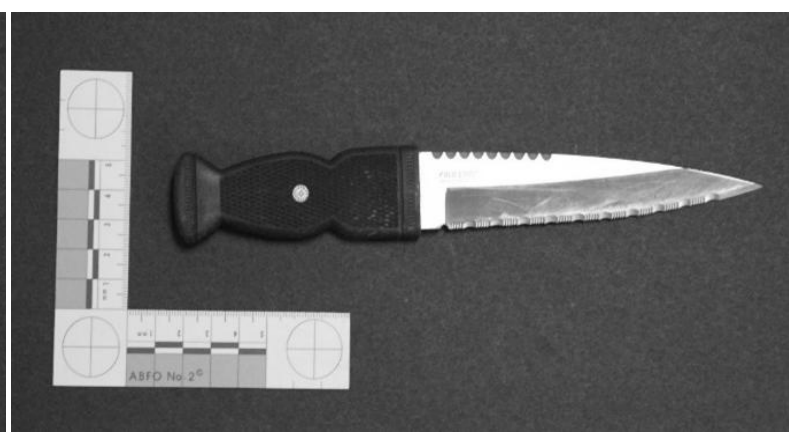

(b)

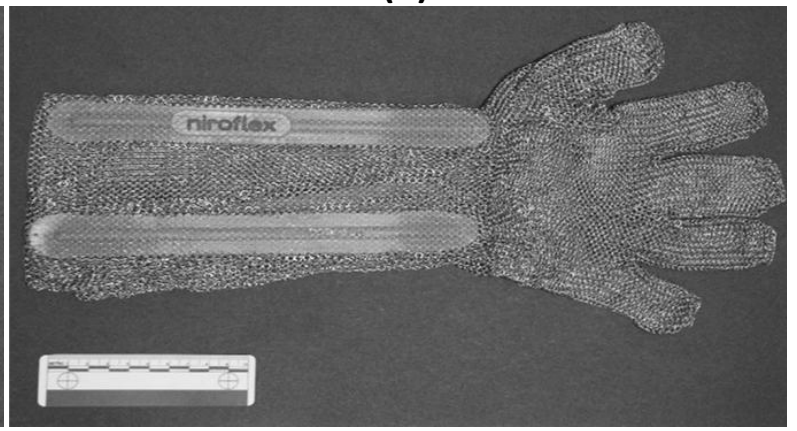

(d)

Ethical approval for this study was granted by ***** (approval number 004_2013). A male trained in the Filipino martial arts discipline of Eskrima ${ }^{3}$ participated in this pilot study. The sharp-weapon expert was given no prior guidelines for the simulated attacks, although he did assume the target (PermaGel ${ }^{\mathrm{TM}}$ torso dressed in a T-shirt) to be right handed. One PermaGel ${ }^{T M}$ torso and one T-shirt were used for each knife type $(n=3)$. The expert approached the target in the manner applicable to the knife used. With the knife drawn, he then carried out a simulated attack on the target using his right hand, which was protected by a chainmail glove. High speed video was used to record each trial with one camera posi-

\footnotetext{
${ }^{3}$ Martial art style originating from the Philippine Islands also known as Arnis or Kali. Eskrima is used by a number of police and military forces around the world as a basis for knife defense training [5].
} 
tioned to record the hand action and impact location and the other positioned behind the participant to identify the participant's overall body movement.

While still mounted on the torso, each severed T-shirt was immediately photographed following the impact trial using a Canon EOS 60D digital camera fitted with a Canon EFS 17 - 85 mm lens. The T-shirts were then carefully removed from the torso and laid flat under no tension with side and sleeve seams aligned. Fabric severances and surrounding features were examined under magnification up to 40x using a Motic Trinocular Zoom SMZ143 N2GG stereo-microscope equipped with a Moticam 480 camera linked to Motic Image Plus, version 2.0 capture software ${ }^{4}$. Fabric severance length ( $>1 \mathrm{~mm}$ ) was measured to the nearest $\mathrm{mm}$ at a minimum of 4 hours after removal of the T-shirt from the torso. This was to simulate a delayed forensic examination during a textile damage investigation, which might affect severance dimensions and appearance. High speed video was then analyzed to determine the mode and sequence of impact.

\footnotetext{
${ }^{4}$ Australian Instrument Services Pty. Ltd., Unit 1 - 2 / 21 Stud Road Bayswater, VIC, 3153, Australia.
} 


\section{Results}

Damage to T-shirts

Photographs of severed T-shirts while mounted on the torso are presented in Figures 4 and 5; severance lengths are provided in Table 2. Damage was affected by the weapon used, thus results are presented for each weapon individually.

Mantis Karambit MK-1 Cinq1: The T-shirt severed with the Mantis Karambit knife showed a distinctive slashing technique compared to the other knives considered; the blade had been used to slash the T-shirt diagonally predominantly in the upper right chest region (Figure 4a). Two of these slashes were over the T-shirt sleeve seam; one fully cut the seam. Slashes made over to the sleeves were perpendicular to the wales due to the garment's construction. The blade tip was also used to create smaller isolated penetrating holes in the T-shirt fabric $(n=9)$ (Figure 5a, examples are circled). Seventeen severances were identified that measured between $2 \mathrm{~mm}$ and $263 \mathrm{~mm}$ in length; the total attack time was <4 s (Table 2).

Cold Steel ${ }^{\circledR}$ Culloden $^{\mathrm{TM}}$ : The T-shirt severed with a Cold Steel ${ }^{\circledR}$ knife (Figure 4b) was primarily slashed, with one isolated hole. A large impact was made to the lower right of the torso (circled in Figure 4b) where the T-shirt fabric was drawn into the simulant and remained after knife withdrawal. The torso's right underarm was also a target (Figure 5b). This particular knife was serrated and some of the severances had a distinctive ragged edged appearance. However, the severance created perpendicular to the wales along the chest center of the torso did not show the same ragged edge characteristics (Figures $4 \mathrm{~b}$ and $5 \mathrm{c}$ ). One severance created parallel to wales (length of T-shirt) was adjacent to a previously created 
severance. Twenty-three severances were identified that measured between $1 \mathrm{~mm}$ and 282 $\mathrm{mm}$ in length; the total attack time was $<4 \mathrm{~s}$ (Table 2 ).

BlackHawk ${ }^{\mathrm{TM}} \mathrm{XSF}^{\mathrm{TM}}$ Micro Plain: The T-shirts severed with the BlackHawk ${ }^{\mathrm{TM}}$ knife (Figure 4c) showed, isolated puncture holes. Some areas of fabric were targeted but not perforated (circled in Figure 5d) and in one instance, the fabric remained in the simulant after knife withdrawal. Severances that were longer in length than blade width were created either perpendicular or horizontal in relation to fabric wales (length of T-shirt). Thirty-four severances were identified that measured between $2 \mathrm{~mm}$ and $44 \mathrm{~mm}$ in length; total attack time was $<5.5 \mathrm{~s}$ (Table 2 ). 
Figure 4a-c T-shirt severances created by each knife while mounted on the torso (a) Mantis Karambit MK-1 Cinq1, (b) Cold Steel ${ }^{\circledR}$ Culloden $^{\mathrm{TM}}$, (c) BlackHawk ${ }^{\mathrm{TM}}$ XSF $^{\mathrm{TM}}$ Micro Plain.

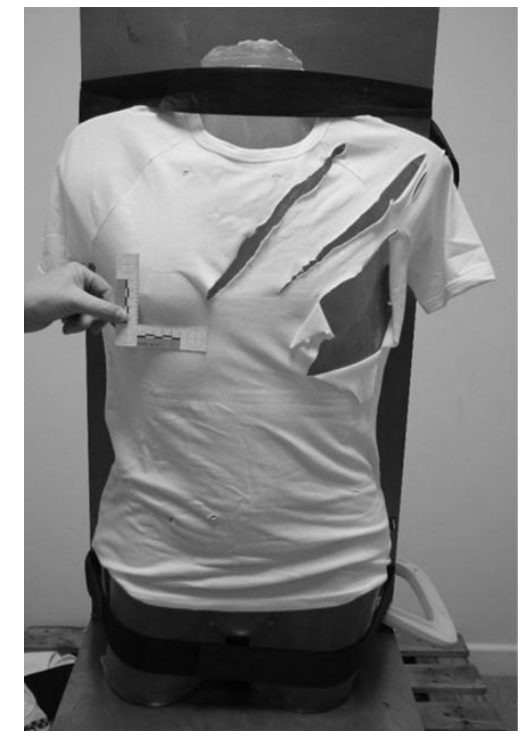

(a)

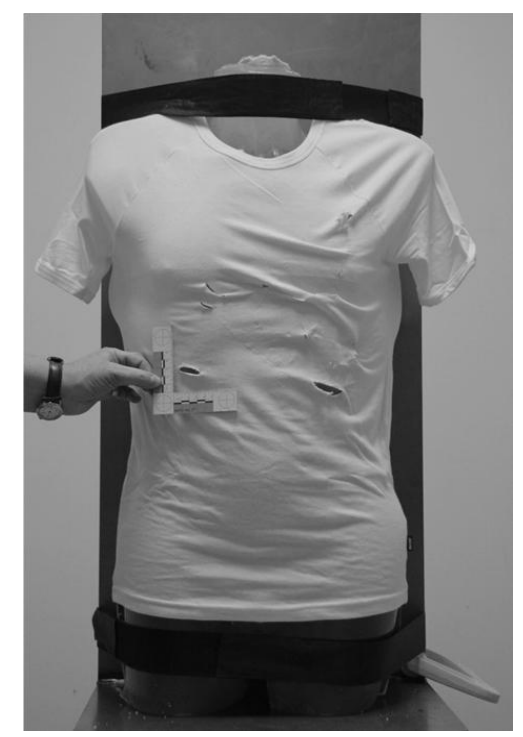

(c)

c)

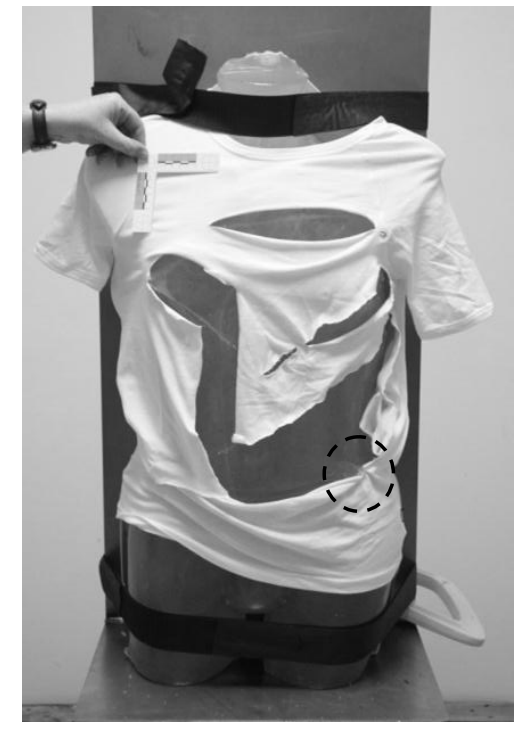

(b) 
Figure 5a-d Additional views of T-shirt severances created by each knife while mounted on the torso (a) Mantis Karambit MK-1 Cinq1, (b and c) Cold Steel $^{\circledR}$ Culloden $^{\mathrm{TM}}$, (d) BlackHawk $^{\mathrm{TM}} \mathrm{XSF}^{\mathrm{TM}}$ Micro Plain.

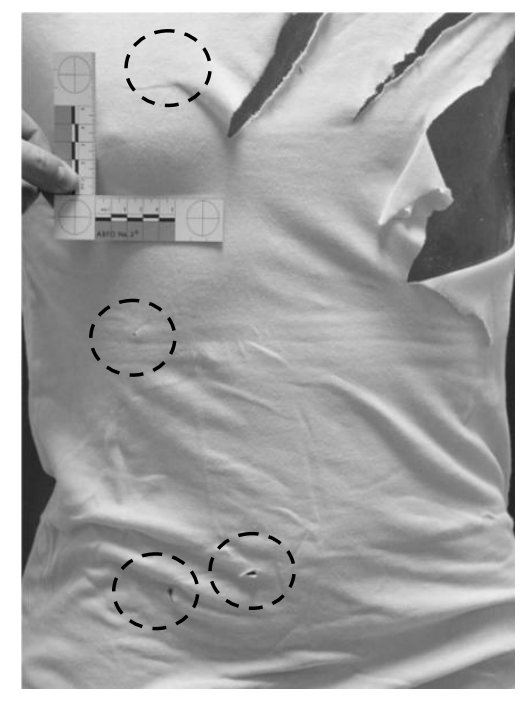

(a)

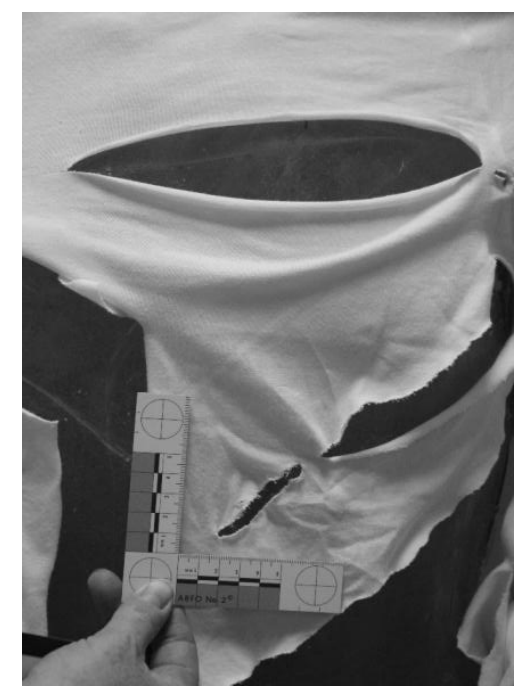

(c)

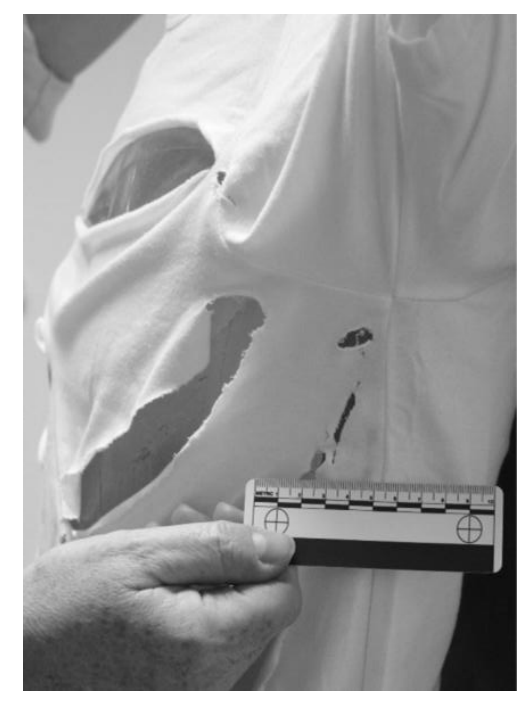

(b)

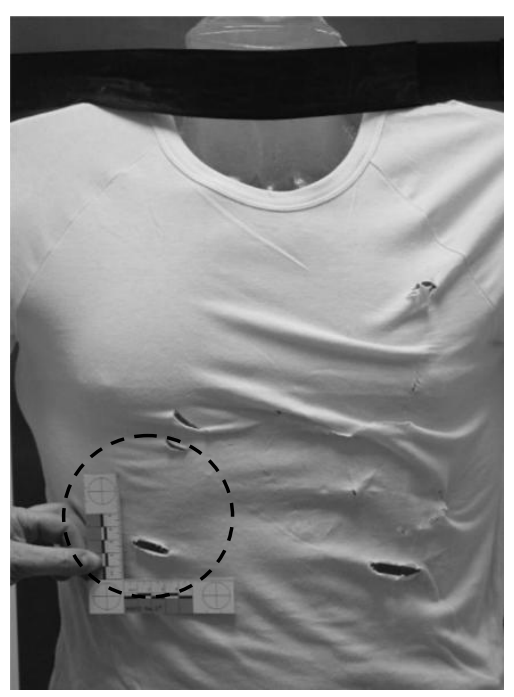

(d) 
Table 2 Summary of severance lengths

\begin{tabular}{|c|c|c|c|c|}
\hline \multirow[b]{2}{*}{ Knife } & \multirow[b]{2}{*}{$\begin{array}{l}\text { Number of } \\
\text { severances } \\
\text { (n) }\end{array}$} & \multicolumn{2}{|c|}{$\begin{array}{l}\text { Severance length } \\
(\mathrm{mm})\end{array}$} & \multirow[b]{2}{*}{$\begin{array}{l}\text { Total attack time } \\
\text { (s) }\end{array}$} \\
\hline & & $\begin{array}{l}\text { Mini- } \\
\text { mum }\end{array}$ & $\begin{array}{l}\text { Maxi- } \\
\text { mum }\end{array}$ & \\
\hline $\begin{array}{l}\text { Mantis Karambit MK-1 } \\
\text { Cinq1 }\end{array}$ & 17 & 2 & 263 & 3.907 \\
\hline Cold Steel $^{\circledR}$ Culloden $^{\mathrm{TM}}$ & 23 & 1 & 282 & 3.905 \\
\hline $\begin{array}{l}\text { BlackHawk }{ }^{\mathrm{TM}} \mathrm{XSF}^{\mathrm{TM}} \mathrm{Mi}- \\
\text { cro Plain }\end{array}$ & 34 & 1 & 44 & 5.368 \\
\hline
\end{tabular}

Typical microscopic images of severances are presented in Figure 6. All knives were used as stabbing and slashing instruments.

Figures 6a-c are typical severances formed when the knives were used to perforate the fabric using a stab motion. The main observations from stab severances were (i) the Mantis Karambit knife appeared to cut the yarns with relatively low displacement (Figure 6a), (ii) the Cold Stee ${ }^{\circledR}$ knife created a jagged severance with multiple unravelled yarns (Figure $6 \mathrm{~b}$ ) and (iii) the BlackHawk ${ }^{\mathrm{TM}}$ knife produced severances with few severed yarns (Figure $6 c)$, which were often not visible when viewed macroscopically. The direction of the blade could be determined in some stab impacts created by the Mantis Karambit and Cold Steel ${ }^{\circledR}$ knives. It was not possible to distinguish the direction of severances created with the BlackHawk $^{\mathrm{TM}}$ knife.

Figures $6 d-f$ are typical severance edges created using a slash technique. The main observation of slash severances were:

(i) The Mantis Karambit severance edges had a 'stepping' pattern (Figure 6d), 
(ii) the Cold Steel ${ }^{\circledR}$ knife created severance with jagged edges and multiple areas of significant yarn unraveling, a trait more commonly seen when the wales were severed diagonally (Figure 6e) and

(iii) the BlackHawk ${ }^{\mathrm{TM}}$ knife produced a variety of characteristics. Either damage was created to the fabric surface partially severing yarns, or for larger slash cuts, the yarns had fibrillated ends which could be interpreted as being more similar to a tear than a cut.

Figure 6a-f Typical microscopic images of severances (magnification $15 \mathrm{x}$ ). Typical stab impact (a) Mantis Karambit MK-1 Cinq1, (b) Cold Steel $^{\circledR}$ Culloden $^{\mathrm{TM}}$, (c) BlackHawk $^{\mathrm{TM}}$ $\mathrm{XSF}^{\mathrm{TM}}$ Micro Plain. Typical slash impact (d) Mantis Karambit MK-1 Cinq1, (e) Cold Steel ${ }^{\circledR}$ Culloden $^{\mathrm{TM}}$, (f) BlackHawk ${ }^{\mathrm{TM}} \mathrm{XSF}^{\mathrm{TM}}$ Micro Plain.

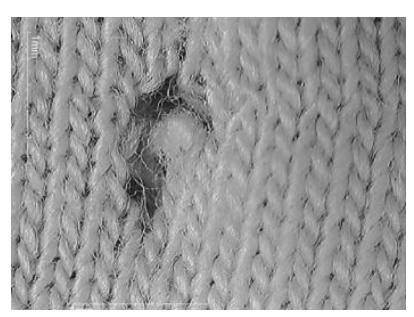

(a)

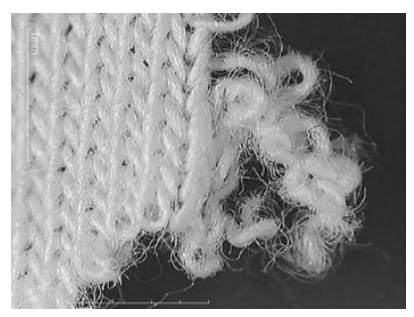

(d)

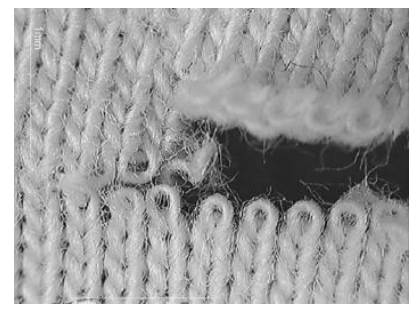

(b)

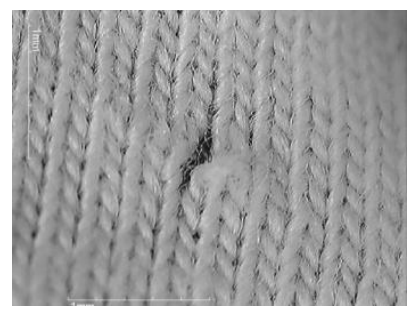

(e)

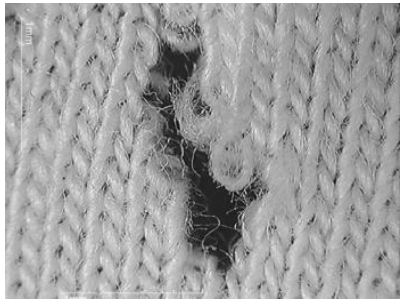

(c)

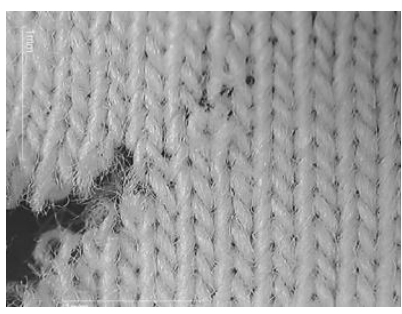

(f) 
High speed video provided supplementary information to the macroscopic and microscopic evaluations of severance damage. Firstly, once the T-shirt was perforated, the participant occasionally pushed the knife to further penetrate the simulant by leveraging power from body position or an assisted push from his left hand (i.e. the hand not holding the knife). Secondly the knife withdrawal did not always follow the same plane as the knife impacted, which created further fabric damage.

When the fabric was severed using a slash technique two characteristics were observed:

(i) the slash was inflicted by directly dragging the knife blade along the fabric surface or

(ii) the slash was initiated after an initial stab penetration, creating severances with a varied axis.

Several attempts were made to slash the T-shirt covered torso with little or no dam-

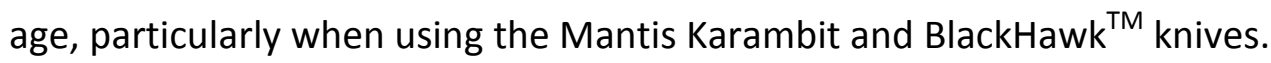

The sequence and direction in which the participant orientated his attack was plotted for the Mantis Karambit (Figure 7). Due to the technique of the simulated attacks, it was not possible to precisely plot the attack sequence for the Cold Steel ${ }^{\circledR}$ and Blackhawk ${ }^{\mathrm{TM}}$ knives. 
Figure 7 Impact sequence and direction of impact in relation to Mantis Karambit MK-1

\section{Cinq1.}

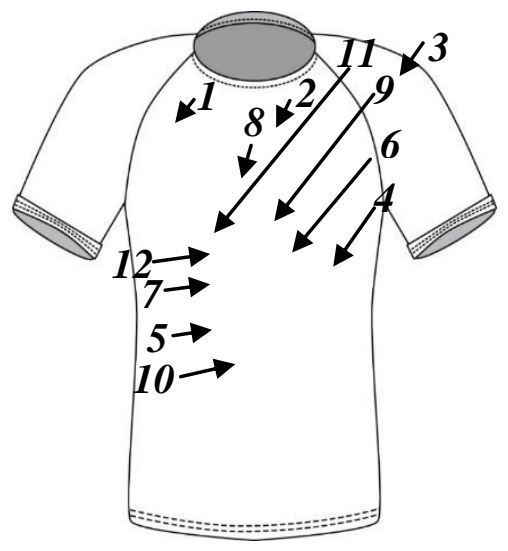

The number of impact strikes attempted by the participant per second on the torso was determined from high speed video (Table 3). The greatest total number and greatest number of strikes per second were noted for the Mantis Karambit knife; the total number of strikes for the other two knives was similar, but the number of strikes made per second with the Blackhawk ${ }^{\mathrm{TM}}$ knife was slightly lower.

Table 3 Summary of recorded attack strikes vs time

\begin{tabular}{|c|c|c|c|}
\hline \multirow[b]{2}{*}{ Knife } & \multirow[b]{2}{*}{$\begin{array}{l}\text { Recorded at- } \\
\text { tack time (s) }\end{array}$} & \multicolumn{2}{|c|}{ Number of strikes recorded } \\
\hline & & Total & Per second \\
\hline Mantis Karambit MK-1 Cinq1 & 3.907 & 12 & 3.1 \\
\hline Cold Steel Culloden ${ }^{\mathrm{TM}}$ & 3.905 & 7 & 1.8 \\
\hline BlackHawk ${ }^{\mathrm{TM}} \mathrm{XSF}^{\mathrm{TM}}$ Micro Plain & 5.368 & 8 & 1.5 \\
\hline
\end{tabular}




\section{Discussion}

Two aspects to this pilot study require further discussion (i) experimental procedure and (ii) severance evaluation.

\section{Experimental procedure}

Particular emphasis should be placed on laboratory simulation practices when recreating physical textile damage caused by knives. In this study a static male torso surrogate manufactured from a tissue simulant was used but limitations were present with this experimental approach. For instance, during a violent attack, the victim's movement will play a role in the attack method of both skilled and unskilled attackers. In particular, the defensive use of the limbs (i.e. arms and legs) and stance become important. A trained user will use the victim's arms to reposition them to open up space for cuts, or the victim may be quickly left vulnerable by having their arms (their first line of defense) neutralized by cuts. The knives used in this study had different handles which determined how the trained sharpweapon user gripped the handle and used the weapon. Observations regarding the influence of knife handle design during human performance have previously been reported (30).

The severance evidence presented in this pilot study highlighted the different appearance of damage created by a trained user with different knives; this is useful information for textile examiners. A victim with multiple sharp force wounds could have been attacked by more than one weapon or perpetrator or as in this pilot study a single perpetrator with a single knife. The scenario might be difficult for a pathologist to determine, partic- 
ularly if no weapons are recovered. As this pilot study has shown, it is possible to inflict varied fabric severance with a single assailant using one knife.

\section{Severance evaluation}

All three knives used in this study were used to create severances that were either diagonal or perpendicular to the wale direction of the fabric. Few severances were created parallel to the wales ${ }^{5}$. A similarity between previous work and this current pilot study was the angle of impact which the participant chooses to strike the target (26). It appeared that trained sharp-weapon users were more likely to impact the target on a varied angle, and remove the weapon on a different angle or twist the knife during withdrawal, easing the release of the knife and increasing wounding to the target (26).

The severance appearance was different when photographed while on the torso in comparison to when removed and laid flat in the laboratory. This was possibly due to a number of reasons including:

(i) tension placed on the fabric,

(ii) support from the underlying tissue simulant,

(iii) drape of the fabric as it was vertically mounted,

(iv) repositioning of the garment during the simulated attack, causing fabric folds and

(v) presence of fabric remaining in the tissue simulant.

\footnotetext{
${ }^{5}$ isolated punctures were categorized separately due to their circular shape
} 
By carefully laying the severed T-shirts flat under no tension and aligning the garment seams, the examination was consistent among all three T-shirts. However, matching the severances to the attack sequence proved to be more difficult with different blades, particularly on the T-shirt severed with the Cold Steel ${ }^{\circledR}$ knife, where more than one slash in a similar area resulted in overlapping severances.

Single jersey fabrics are considered to be an unstable structure which results in curling of severed edges. Curling has been acknowledged to be associated with severed single jersey fabrics. In this study, curling was observed :

(i) when severed perpendicular to the wales, the severed edges curled towards the technical front of the fabric and

(ii) when severed parallel to the wales, the severed edges curled to the technical back of the fabric.

\section{Conclusions}

This pilot study demonstrated variability in severances associated with an attack from an expert sharp-weapon user. This variability occurred (1) within a single attack due to variation of technique used, and (2) among attacks using different knives. It is possible that a textile examiner presented with damaged clothing similar to those created in this pilot study would find it difficult to draw firm conclusions from it, and might conclude the attack was due to several perpetrators with different weapons. The pilot study presented in this paper reinforces the variability of severances that can be created in a clothing layer during a knife $\operatorname{attack}(20)$. 
The conclusions drawn from this pilot study are limited by the use of a single expert user and the three knives used, but the work does raise important issues for the forensic textile science community concerned with textile damage to consider.

\title{
Acknowledgements
}

\author{
**** acknowledges receipt of a *** Visiting Research Studentship and a Research Training \\ Scheme (RTS) PhD tuition scholarship at **** University.
}

\section{References}

1. Office for National Statistics. Crime in England and Wales, Year Ending June 2014. London, UK: Office for National Statistics, 201416 October 2014. Report No.

2. Karlsson T. Homicidal and suicidal sharp force fatalities in Stockholm, Sweden. Orientation of entrance wounds in stabs gives information in the classification. Forensic Science International. 1998;93:21-32.

3. Ormstad K, Karlsson T, Enkler L, Rajs J. Patterns in sharp force fatalities - a comprehensive forensic medical study. Journal of Forensic Sciences. 1986;31:529-42.

4. Brennan IR, Moore SC, Shepherd JP. Aggression and attitudes to time and risk in weapon-using violent offenders. Psychiatry Research. 2009;178:536-9.

5. The Vikings Web Design Team. The Vikings 2016 [10 April 2016]. Available from: http://www.vikingsonline.org.uk/.

6. FDC. The Sealed Knot 2016 [10 April 2016]. Available from: http://www.thesealedknot.org.uk/. 
7. Godhania K. Eskrima: Fillipino Martial Art. Ramsbury, UK: Crowood Press Limited; 2010.

8. Loriega J. Sevillian Steel: The Traditional Knife-Fighting Arts of Spain. Boulder, USA: Paladin Press; 1999.

9. Maynard R. Tanto: Japanese Knives and Knife Fighting. Glastonbury, UK: Unique Publications; 1986.

10. Spierenburg L. Men and Violence: Gender, Honor and Rituals in Modern Europe and America. Ohio, USA: Ohio State University Press; 1988.

11. Stephens FJ, Boxall M. Fighting Knives: An Illustrated Guide to Fighting Knives and Military Survival Weapons of the World. London, UK: Arms and Armour Press; 1980.

12. Taff ML, Boglioli LR. Science and politics of cutting and stabbing injuries in the USA. Journal of Clinical Forensic Medicine. 1998;5:80-4.

13. Johnson N. Physical damage to textiles. In: Vernon J, Berwick D, editors. Police Technology: Asia Pacific Police Technology Conference. Canberra: Australian Institute of Criminology; 1991. p. 121-8.

14. Sitiene R, Zakaras A, Pauliukevicius A, Kisielius. Morphologic, expermiental comparitive investigation as an identification of the injuring instrument method. Forensic Science International. 2007;167:255-60.

15. Prahlow JA. Sharp force injury deaths, in: Forensic Pathology for Police, Death Investigators, Attorneys, and Forensic Scientists. New York, USA: Humana Press; 2010. 16. Di Maio DJ, Di Maio VJ. Wounds due to pointed and sharp, edged weapons. Forensic Pathology. New York: CRC Press; 1993. p. 187-228.

17. Henderson JM, Morgan SE, Patel F, Tiplady ME. Patterns of non-firearm homicide. Journal of Clinical Forensic Medicine. 2005;12:128-32. 
18. Ambade VN, Godbole HV. Comparison of wound patterns in homicide by sharp and blunt force. Forensic Science International. 2006;156:166-70.

19. Taupin JM, Cwiklik C. Scientific protocols for forensic examination of clothing: CRC Press; 2010.

20. Cowper EJ, Carr DJ, Horsfall I, Fergusson SM. The effect of fabric and stabbing variables on severance appearance. Forensic Science International. 2015;249:214-24.

21. Kemp SE, Carr DJ, Kieser J, Niven BE, Taylor MC. Forensic evidence in apparel fabrics due to stab events. Forensic Science International. 2009;191:86-96.

22. Costello PA, Lawton ME. Do stab cuts reflect the weapon that made them? Journal of Forensic Science Society. 1990;30:89-95.

23. Taupin JM. Comparing the alleged weapon with damage to clothing- the value of multiple layers and fabrics. Journal of Forensic Science. 1999;44:205-7.

24. Monahan DJ, Harding HWJ. Damage to clothing - cuts and tears. Journal of Forensic Science. 1990;35:901-12.

25. Bleetman A, Watson $\mathrm{CH}$, Horsfall I, Champion SM. Wounding patterns and human performance in knife attacks: optimising the protection provided by knife resistant body armour. Journal of Clinical Forensic Medicine. 2003;10:243-8.

26. Bleetman A, Hughes $\mathrm{H}$, Gupta V. Assailant technique in knife slash attacks. Journal of Clinical Forensic Medicine. 2003;10:1-3.

27. International Organization for Standardization. ISO 7250-1:2008, Basic human body measurements for technological design - Part 1: Body measurement definitions and landmarks. Geneva, Switzerland: International Organization for Standardization; 2008. 
28. Mabbott A, Carr D, Champion S, Malbon C, Tichler C. Comparison of $10 \%$ gelatine, $20 \%$ gelatine and PermaGel ${ }^{\mathrm{TM}}$ for ballistic testing. Proceedings of the International Symposium on Ballistics: 22-26 April 2013; Freiburg, Germany. 2013:648-54.

29. International Organization for Standardization. ISO 139:2005 Textiles - Standard atmospheres for conditioning and testing. Geneva: International Organization for Standardization, 2005.

30. Horsfall I, Watson $\mathrm{CH}$, Champion SM, Prosser PD, Ringrose T. The effect of knife handle shape on stabbing performance. Applied Ergonomics. 2005;36(4):505-11. 